\title{
RECONSTRUÇÃO DA MEMÓRIA SOCIAL ATRAVÉS DE PRÁTICAS CULTURAIS NA BIBLIOTECA CENTRAL DA UNIVERSIDADE FEDERAL DE SANTA MARIA/RS
}

\author{
LIZANDRA VELEDA ARABIDIAN ${ }^{*}$
}

\begin{abstract}
RESUMO
A universidade exerce importante função na sociedade, pois é considerado um espaço fundamental para a construção da identidade sociocultural de um país. Neste contexto, apresenta-se a biblioteca como lugar fundamental na construção dos sujeitos sociais, em consonância com a função social que a universidade desempenha. Partindo dessa premissa, este trabalho tem o objetivo de apresentar a função social da biblioteca universitária enquanto lugar de memória, como um espaço de práticas culturais, onde, através da reconstrução da sua memória social, são elaboradas representações, contribuindo para a preservação e difusão da sua memória, por intermédio de exposições que marcaram a sua história no âmbito da Instituição.
\end{abstract}

PALAVRAS-CHAVE: Memória. Cultura. Biblioteca.

\begin{abstract}
The university plays an important role in society, since it is considered a fundamental space for the construction of the socio-cultural identity of a country. And in this context the library is presented as a fundamental place in the construction of social subjects, in harmony with the social function that the university plays. Based on this premise, this paper aims to present the social function of the university library as a place of memory, as a space of cultural practices, where through the reconstruction of its social memory, representations are elaborated, contributing to the preservation and diffusion of its memory, through exhibitions that marked its history within the Institution.
\end{abstract}

KEYWORDS: Memory. Culture. Library.

* Bibliotecária da Universidade Federal de Santa Maria. Especialista em Gestão em Arquivos pela Universidade Federal Santa Maria. Mestre em Patrimônio Cultural pela Universidade Federal Santa Maria. Doutoranda pelo Programa de Pós-Graduação em Memória Social e Bens Culturais pela Universidade La Salle/Canoas. 


\section{INTRODUÇÃO}

Este artigo apresenta a função social da biblioteca universitária enquanto lugar de memória, ressaltando sua conexão com a instituição da qual faz parte, que é a universidade. Suas produções culturais e intelectuais são selecionadas, armazenadas e divulgadas, sendo tais informações necessárias para a pesquisa e desenvolvimento da nossa comunidade, apresentando-se, portanto, como lugar de memória.

A biblioteca, enquanto parte integrante da universidade, deve atuar de forma compromissada com o crescimento e formação do indivíduo. Sua função contribui, decisivamente, para o ensino, a pesquisa e a extensão; assumindo, assim, seu papel social de promover o tratamento documental e a disseminação da informação em prol do desenvolvimento da educação, da ciência e da cultura. Os seus espaços precisam ser dinâmicos e vivos, tornando-a acessível à herança da cultura de um povo, captado em sua memória.

Desse modo, observa-se que é possível fundamentar este estudo, tendo como base as discussões de autores como Halbwachs, com o conceito de memória coletiva; Nora, com a noção de lugares de memória; Oliveira e Rodrigues, retratando as categorias da memória; Gondar, na questão da memória social, entre outros.

\section{MEMÓRIA, CULTURA E IDENTIDADE}

Refletindo por intermédio da obra de Le Goff, o conceito de memória é indiscutível no sentido de "[...] como propriedade de conservar certas informações, remete-nos, em primeiro lugar, a um conjunto de funções psíquicas, graças às quais o homem pode atualizar impressões ou informações passadas, ou que ele representa como passadas" (LE GOFF, 1992, p. 423).

Para Nora, "a memória é a vida, e nesse sentido, ela está em permanente evolução, aberta à dialética da lembrança e do esquecimento, vulnerável a todos os usos e manipulações, susceptível de longas latências e de repentinas revitalizações." (NORA, 1993, p. 9).

Oliveira e Rodrigues (2011) destacam que os estudos nas áreas de Biblioteconomia e Ciência da Informação retratam a memória em três categorias: memória humana, memória social e memória artificial. Diz respeito aos registros da informação como memória socialmente construída, representada e compartilhada por um grupo, estejam eles institucionalizados (compondo os acervos de 
arquivos, bibliotecas e museus) ou não.

Para Gondar, a memória social é vista em caráter "[...] transdisciplinar e se produz nos entrecruzamentos da filosofia, da psicologia, das neurociências, das ciências da informação [...] atravessando suas fronteiras e fertilizando um novo campo de problemas, onde o dissentimento resulta em novas ideias." (GONDAR, 2004, p. 4 apud HOLLÓS, 2010, p. 30).

Halbwachs destaca as memórias coletivas, que não deixam de apresentar o seu aspecto social. Para ele, mesmo que aparentemente particular, a memória remete a um grupo; o indivíduo carrega em si a lembrança, mas está sempre interagindo na sociedade, já que "nossas lembranças permanecem coletivas e nos são lembradas por outros, ainda que se trate de eventos em que somente nós estivemos envolvidos e objetos que somente nós vimos" (HALBWACHS, 2006, p. 30). Afirma, ainda, que, quando um grupo reúne suas lembranças, é possível descrever, com certa exatidão, fatos e objetos que presenciaram.

No mais, se a memória coletiva tira sua força e sua duração do fato de ter por suporte um conjunto de homens, não obstante eles são indivíduos que se lembram, enquanto membros do grupo. Dessa massa de lembranças comuns, e que se apóiam uma sobre a outra, não são as mesmas que aparecerão com mais intensidade para cada um deles. Diríamos voluntariamente que cada memória individual é um ponto de vista sobre a memória coletiva, que este ponto de vista muda conforme o lugar que ali eu ocupo, e que este lugar mesmo muda segundo as relações que mantenho com outros meios. Não é de admirar que, do instrumento comum, nem todos aproveitam do mesmo modo. Todavia quando tentamos explicar essa diversidade voltamos sempre a uma combinação de influências que são, todas, de natureza social (HALBWACHS, 1990, p. 51).

A diferença entre a memória individual e memória coletiva aparece bem caracterizada na citação deste autor. Destaca-se, dessa passagem algumas características importantes na relação memória individual/coletiva, como: os indivíduos recordam como membros de grupos; a memória coletiva tem por suporte o conjunto das pessoas que integram o grupo; o instrumento comum é a memória coletiva; a memória individual é um ponto de vista da memória coletiva; este ponto de vista é mutável, dependendo das relações com outros meios sociais.

Diante disso, as instituições como museus, bibliotecas e arquivos reúnem, em seus acervos, importantes documentos no que diz respeito à memória social; tornando-se, assim, um lugar de memória. Essas instituições são locais nos quais os pesquisadores 
exercem suas práticas. Considerados lugares de memória, bem como a memória das instituições, resultam em apropriações dos conceitos de memória social e memória coletiva, bem como emprego de múltiplas extensões, tais como: instituições de memória, centros de memória, arquivos de memória e entidades de memória.

O termo "lugar de memória" firmado por Nora (1993, p. 13) estabelece que eles nascem e vivem do sentimento de que não há memória instintiva, de que é preciso criar arquivos. Assim, Nora destaca que: "[...] se o que eles defendem não estivesse ameaçado, não se teria, tão pouco, a necessidade de construí-los. Se vivêssemos verdadeiramente as lembranças que eles envolvem, eles seriam inúteis". (NORA, 1993, p. 13).

Vieira (2015) observa que, quanto menos se vive a memória no interior, maior a necessidade de suportes exteriores. Nessas extensões, são constantes as referências a uma dinâmica da memória possibilitada pela informação registrada, levando à construção, reconstrução, formação, manutenção, recuperação, preservação, conservação, valorização, incorporação, interação, exclusão e destruição da memória (OLIVEIRA; RODRIGUES, 2011). Tal reflexão destaca, mais uma vez, a função social da biblioteca, agora como lugar de memória, que é fruto de produções culturais e identitárias de um povo.

\section{A BIBLIOTECA CENTRAL DA UFSM}

A Biblioteca Central da UFSM - Biblioteca Central Manoel Marques de Souza, "Conde de Porto Alegre" - é um órgão suplementar da Reitoria e está vinculada à Pró-Reitoria de Administração. Com o propósito de contribuir para a transformação sociocultural e econômica da Região Central do Rio Grande do Sul; configura-se, portanto, como parte da história do desenvolvimento do Estado e principalmente da cidade de Santa Maria. Com projeto arquitetônico arrojado e moderno para a época, visa contribuir para o desenvolvimento da ciência, do saber e da tecnologia, bem como para a formação da comunidade local e regional através de projetos de extensão.

Foi fundada em dezembro de 1960 e reuniu as coleções bibliográficas das Faculdades de Farmácia, Enfermagem, Medicina, Odontologia, Veterinária, Agronomia, Belas Artes, Politécnica, Filosofia, Ciências e Letras. Até 1971, a Biblioteca Central esteve localizada no, então, prédio da Administração Central - a antiga Reitoria, na Rua Floriano Peixoto, no centro da cidade. Em 1972, mudou-se para o novo prédio, no Campus. A partir de 1978, algumas modificações nos serviços prestados aos usuários foram implementadas, como: 
empréstimo domiciliar a toda a comunidade universitária e livre acesso às estantes, assim como mudanças na ocupação do espaço físico, proporcionando melhor distribuição do acervo.

Em 1979, acompanhando a tendência nacional, foi implantado o serviço de "comutação bibliográfica", ou seja, permuta de artigos de periódicos com outras instituições. Quanto à estrutura, houve a reforma do prédio, com expansão e melhor aproveitamento do espaço físico, instalação de cabines de estudo individual e salões para estudo em grupo. Em 1991, iniciou o processo de informatização, com a adoção do Sistema de Automação de Bibliotecas (SAB2), em seguida, Bibliotech e, por fim, o Sistema Integrado para o Ensino (SIE), transferindo os dados de sua base bibliográfica para o novo sistema desenvolvido pelo Centro de Processamento de Dados da UFSM. No ano de 2000, foi lançado pela CAPES o Portal de Periódicos, permitindo o acesso online a artigos de periódicos científicos.

A Biblioteca Digital de Teses e Dissertações da UFSM foi lançada em 2006 e, em 2009, foi feito o lançamento do site da Biblioteca Central. A partir dessa data, houve a implantação das Bibliotecas Setoriais Descentralizadas de Silveira Martins, Frederico Westphalen e Palmeira das Missões.

Os acervos das Bibliotecas da UFSM incluem obras científicas e técnicas, obras de referência, periódicos gerais e especializados. Atualmente, a Biblioteca Central está em fase de ampliação, para melhor atender às demandas do ensino, da pesquisa e da extensão da UFSM. Para comportar essa expansão e melhor atender à comunidade, a Biblioteca está sendo aumentada em $1900 \mathrm{~m}^{2}$. Nesse projeto de reformulação do espaço da biblioteca, foram previstas melhorias nas acomodações de seu acervo bibliográfico e ampliações dos locais destinados à convivência.

O desenvolvimento da Biblioteca está acompanhando o crescimento da Universidade, pois não há ensino sem biblioteca e o oferecimento de novos cursos exige, necessariamente, a ampliação constante do acervo. A exigência de proximidade dos materiais bibliográficos com os professores e alunos ocasionou o surgimento das bibliotecas setoriais, localizadas nos centros de ensino. $O$ esforço para qualificação da coleção bibliográfica e dos serviços oferecidos à comunidade universitária é permanente e nunca satisfatório. Os recursos são sempre insuficientes, mas a meta principal é melhorar sempre e buscar a excelência das bibliotecas na UFSM. O Sistema de Bibliotecas coordena tecnicamente doze bibliotecas setoriais, sendo nove em Santa Maria, uma em Frederico 
Westphalen, uma em Palmeira das Missões e tem como objetivo colocar à disposição da comunidade universitária a informação bibliográfica atualizada e de forma organizada, favorecendo o desenvolvimento do ensino, da pesquisa e da extensão.

Nesses 40 anos de funcionamento e sempre buscando a valorização da sua história, uma exposição fotográfica foi promovida em comemoração ao seu aniversário de inauguração. Nela, pretendeu-se reconstruir e divulgar a sua história, bem como homenagear servidores ativos e inativos e demais colaboradores que participaram da sua trajetória e contribuíram com o eficaz desempenho das suas atividades. A exposição integrou a programação comemorativa dos 50 anos da Universidade Federal de Santa Maria.

No discurso de abertura, uma homenagem póstuma à primeira diretora da Biblioteca Central, Selene Bernardi Parreira, foi apresentada:

Ao estudante dedicamos nosso trabalho, verdadeira chave para a utilização eficiente dos livros e da Biblioteca. Que os livros possam abrir tua mente para novos caminhos do saber, trazendo-te satisfação nos estudos, e mais tarde, na vida profissional, eles sejam fonte preciosa de informações e prazer intelectual (O Quero Quero, 1973).

Há 40 anos, Selene Bernardi Parreira iniciava com essas palavras seu discurso na inauguração do prédio da Biblioteca Central Manoel Marques de Souza, Conde de Porto Alegre. Era um domingo, 3 de setembro de 1972, e foi nesse dia que Selene, a diretora pioneira da Biblioteca Central, recebeu a comunidade universitária pela primeira vez.

A exposição fotográfica ocorreu no hall da biblioteca e requereu meses de organização e planejamento pelas bibliotecárias de referência da Biblioteca Central, que contaram com a colaboração de bolsistas e diversos setores da biblioteca, das Bibliotecas Setoriais e do acervo fotográfico do Arquivo da Instituição na coleta de dados e fotografias. Na cerimônia de abertura, foi oferecido um coquetel aos servidores ativos e inativos que a prestigiaram. Além dos banners com as fotografias, foi criado um marcador de página em comemoração aos 50 anos da Universidade e um bloco de notas, com o intuito de divulgar a importância da preservação do acervo bibliográfico. Também integrou em sua estrutura um mural e um livro de visitas para o registro dos visitantes e suas manifestações em relação à exposição proposta.

Considera-se que o objetivo da exposição fotográfica, inédita até então, foi alcançado uma vez que atraiu a atenção da comunidade universitária. Diversas notícias sobre a exposição foram 
publicadas na página da Biblioteca e na da Universidade, colocando-a em evidência nos canais formais de comunicação institucional, assim como nos jornais e rádios locais.

Ademais, propiciou uma extraordinária interação entre os servidores ativos e inativos, que trouxeram fotos para contribuir com a iniciativa e reconstruíram detalhes da sua história, desconhecida, até então, por alguns colaboradores do quadro funcional.

Por fim, originou um álbum virtual intitulado "38 anos da Biblioteca Central", cujo acesso permanece aberto a todos os interessados através da página institucional.

\section{CONCLUSÃO}

Percebeu-se que a exposição realizada contribuiu para a reconstrução e divulgação da memória e história da Biblioteca Central da UFSM, além de oportunizar a promoção dos seus serviços e atividades entre a comunidade acadêmica.

Além disso, suscitou a confraternização e a integração entre servidores e demais colaboradores, bem como lhes conferiu a devida homenagem pelo exercício das suas atribuições ao encontro da eficácia das atividades e serviços prestados pela biblioteca.

Nessa trajetória de 40 anos, é importante salientar o esforço e a dedicação da equipe de trabalho, os técnicos administrativos e bolsistas que priorizam o atendimento e a satisfação do usuário, colaborando, inclusive, para a efetivação do amplo horário de atendimento oferecido atualmente, que ocorre nos três turnos manhã, tarde e noite - na constante busca pela excelência no atendimento aos usuários.

Para finalizar, eventos como este serão sempre muito bem vindos e prestigiados, pois, segundo Halbwachs (2004), o passado é reconstruído com os olhos no presente, o grupo é o suporte da memória coletiva, cujos elementos são as memórias individuais.

Desse modo, pretendeu-se promover e divulgar a Biblioteca e seus serviços, a fim de instigar o reconhecimento e a aproximação da comunidade acadêmica enquanto partícipes da história da Instituição.

Recebido em: 19 fev. 2019. Aceito em: 19 fev. 2019.

\section{REFERÊNCIAS BIBLIOGRÁFICAS}

ARABIDIAN, Lizandra Veleda. 40 anos da Biblioteca Central: um prédio 
cheio de histórias. Entrevista concedida à Luciane Treulieb. Disponível em: http://site.ufsm.br/noticias/exibir/4350. Acesso em: 25 abr. 2018.

ARABIDIAN, Lizandra Veleda; MAISONAVE, Simone. História para além dos livros. Entrevista concedida à Manuela llha. Disponível em: http://w3.ufsm.br/infocampus/?p=3289. Acesso em: 25 abr. 2018.

CHARTIER, R. A história cultural, entre práticas e representações. Rio de Janeiro, RJ: Editora Bertrand Brasil, S. A., 1990.

COORDENADORIA DE COMUNICAÇÃO SOCIAL DA UFSM. Biblioteca Central realiza exposição fotográfica para comemoração dos seus 38 anos. Disponivel em: http://sucuri.ufsm.br/noticias/noticia. php?id=30464. Acesso em: 19 Abril 2018.

HALBWACHS, Maurice. A memória coletiva. São Paulo: Vértice/Editora Revista dos Tribunais, 1990.

HALBWACHS, Maurice. A memória coletiva. São Paulo: Centauro, 2004.

HALBWACHS, M. A memória coletiva. Trad. de Beatriz Sidou. São Paulo: Centauro, 2006.

HOLLÓS, Adriana Cox. Preservação e memória social. In: SILVA, Rubens Ribeiro Gonçalves da. et al. (Orgs.). Cultura, representação e informação digitais. Salvador: EDUFBA, 2010. Disponível em: https://repositorio.ufba.br/ri/bitstream/ri/7335/1/cultura-representacaoinformacao-digitais-RI.pdf. Acesso em: 25 abr. 2018.

LE GOFF, Jacques. História e memória. Campinas: Ed. Unicamp, 1992.

NORA, Pierre. Entre memória e história: a problemática dos lugares. Projeto História, São Paulo, n. 10, p. 7-28, dez., 1993. Disponível em: http://revistas. pucsp.br/index.php/revph/ article/viewFile/12101/8763. Acesso em: 25 abr. 2018.

OLIVEIRA, Eliane Braga de; RODRIGUES, Georgete Medleg. O conceito de memória na Ciência da Informação: análise das teses e dissertações dos programas de pós-graduação no Brasil. Liinc em Revista, Rio de janeiro, v. 7, n. 1, p. 31-328, mar., 2011. Disponível em: file:///home/chronos/ue4a9f2a21f4423ada89bdc9baabc907fe6995d57/Downloads/3302-8087-1PB.pdf. Acesso em: 25 abr. 2018.

PÁGINA DA BIBLIOTECA CENTRAL. Arquivo dos álbuns de site da Biblioteca Central. Disponível em: https://picasaweb.google.com/ 105060064471807750445. Acesso em: 25 abr. 2018.

Revista O Quero Quero. Santa Maria : UFSM, ano 1, n.1, abr. 1973.

VIEIRA, Itala Maduell. A memória em Maurice Halbwachs, Pierre Nora e Michael Pollak. In: Encontro Regional Sudeste de História oral: dimensões do público; comunidades de sentido e narrativas políticas, 11, 2015, Niterói, RJ. Anais[...]. Niterói, RJ: UFF, 2015. Disponível em: http://www.sudeste2015.historiaoral.org.br/resources/anais/9/1429129701_A RQUIVO_Memoria_Itala_Maduell.pdf. Acesso em: 25 abr. 2018. 